http://jmscr.igmpublication.org/home/

ISSN (e)-2347-176x ISSN (p) 2455-0450

crossref DOI: https://dx.doi.org/10.18535/jmscr/v9i6.34

Journal Of Medical Science And Clinical Research

\title{
Recent Anti-Epileptic Drugs in Seizure Disorders in Cerebral Palsy
}

\author{
Authors \\ Dr Manvi Katoch ${ }^{1}$, Dr Parmananda Roy ${ }^{2}$, Dr Shiwani Thakur ${ }^{3}$ \\ ${ }^{1}$ Anaesthesiologist, Zonal Hospital, Dharamshala, H.P. \\ ${ }^{2,3}$ Senior Resident, Department of Pediatrics, JLNMCH Bhagalpur, Bihar \\ *Corresponding Author \\ Dr Parmananda Roy \\ Senior Resident, Department of Pediatrics, JLNMCH Bhagalpur, Bihar
}

\begin{abstract}
Cerebral Palsy (CP) is a group of permanent disorder of movement and posture causing limitation of activity, attributable to non-progressive disturbance that occurred in developing fetal or infant brain often accompanied by disturbance of sensation, perception, cognition, communication and behaviour, epilepsy and secondary musculoskeletal problems. CP results from permanent single time insult to the developing brain. Though the insult itself is non progressive, manifestations changes due to natural progression.
\end{abstract}

Keywords: cerebral palsy (CP), seizures, anti-epileptic drugs (AEDs), Lennox Gastautsyndrome, mental retardation.

\section{Introduction}

It was Dr. William John Little who first described the concepts of cerebral palsy and it was termed after him as Little's disease.

Incidence of cerebral palsy $(\mathrm{CP})$ is 10 lac per year in our country whereas prevalence is $>4$ per 1,000 live birth. Ratio of male to female prevalence of $\mathrm{CP}$ is 1.4:1.Causes of cerebral palsy are as follows-Congenital causes- 59.8\%, Acquired causes-17.8\%, CNS infections-57.4\%, Kernicterus-30\%, Hypoxic ischemic encephalopathy-10-20\%, Intracranial bleed> $7.4 \%$, Mixed causes $-22.4 \%$. $43 \%$ of cerebral palsy (CP) cases can be diagnosed by 6 months and $70 \%$ by one year.

Seizure in CP is mostly due to brain damage at the time of birth but difficult to detect in early infancy as patient makes unexpected movements during this period. CP patients are more prone to febrile seizures. Seizures in patients of CP \&mental retardation (MR) pose difficulty in diagnosis because neither the patient can describe the events nor the parents appreciate the seizure due to preoccupied mind with other features of $\mathrm{CP}$.

\section{Seizures in CP: Discussion}

Pathogenesis- Excito-oxidative and inflammatory cascade play role in the pathogenesis. Free radical mediated injury occurs to brain cell. Male neurons are more susceptible than female that is why $\mathrm{CP}$ is more common in males. Immature neurons are more prone to injury.

Primary energy failure (upto 6hrs of birth) Decreased energy rich substances like ATP \& 
phosphocreatine leads to activation of enzymes like lipases, proteases with increased influx of intracellular $\mathrm{Ca}^{2+}$. This causes loss of intracerebral homeostasis due to failure of cellular mitochondrial energy metabolism leading to anaerobic metabolism which results in hyper lacticacidemia, hypoglycemia and increased excitatory amino acids.

Secondary energy failure (latent period-6 to 15hrs)-There is activation of inflammatory response during reperfusion and reoxygenation. The initial hypoxic injury results in an area of infarction, the immediate area surrounding this area is termed as pneumbra. It shows changes in the form of neuronal necrosis or apoptosis, leading to activation of nitric oxide synthase and formation of free radicals. This triggers apoptosis and necrosis which increases accumulation of excitatory neurotransmittors in the cells causing extensive neuronal injury.

Tertiary level brain injury-Irreversible cellular energy failure leads to impaired brain development and sensitization of immune system to inflammation and low endogenous trophical factors causing impaired oligodendrocytes maturation, myelination and repair of the injured brain cells.

Types of Seizures in CP- Seizures in CP can begin at any interval of time, especially in hemiplegic CP. In some hemiplegic and spastic tetraplegic $\mathrm{CP}$, seizures may be extremely severe. The incidence of seizures is highest in patients with quadriplegic and hemiplegic CP whereas lowest in dystonic and spastic diplegic CP. In $61 \%$ cases, onset of seizures is within first year or may extend to second year of life. Severe the CP, earlier the onset of seizures. More than $60 \%$ of quadriplegic and diplegic $\mathrm{CP}$ have onset of seizures within first year of age. About $60 \%$ of hemiplegic $\mathrm{CP}$ has their first seizure episode after one year of age. Seizure can be seen in almost all cases of ataxic $\mathrm{CP}$.
$50 \%$ of Quadriplegic CP present with GTCS type. Twitching, nodding and vacant spells may be present in some cases.

Hemiplegic CP-Generalized or focal seizures are the most common. Focal seizures of months duration may convert into secondary generalization.

Spastic Diplegia- Seizures are mostly GTCS type. Athetotic CP-Absence seizures are more common due to lesion of basal ganglia.

All types of seizures can be seen, which depends upon the location and period of brain injuryGTCS are the most common (38.1\%), Focal seizure (33.4\%), Infantile spasm (22\%), Myoclonic jerks (14.3\%), Absence seizure (4.5\%), Lennox Gastaut syndrome.

\section{Management of seizures in CP:}

Before prescribing antiepileptic drug, we should establish a firm diagnosis and categorize the seizure type. History taking is the corner stone of diagnosis. Video recording of episode with EEG monitoring should be done. CT or MRI should be done to rule out structural brain damage. Treatment should begin with a single drug given at increasing dosage until seizures are controlled. Combination of drugs is more effective than single drug, but the maximum dose of single drug should be achieved before adding next antiepileptic drug (AED).

Drugs are added one at a time and are withdrawn slowly to prevent status epilepticus. Drug therapy is an adjunct to control the seizure and must not preclude the use of psychotherapeutic and general hygienic measures. AEDs reduces frequency and severity of seizures and help the patient with mood swings and outburst but does not cure seizure. Seizures in $\mathrm{CP}$ are often refractory to therapy, it may lead to excessive doses of drugs in an attempt to control the attack. As a result, patient may become overactive, aggressive, destructive and even uncontrollable or alternatively he or she may become apathetic and somnolent. Chronic side effects of drugs can occur such as folate deficiency, vitamin D deficiency 
etc. If seizures are not controlled after adequate dose \& duration with AEDs, review the diagnosis, compliance \& any other preventable precipitant.

Then consider a second monotherapy, alternative approach is to add a second drug, observe for efficacy and then slowly withdraw the first one. When subsequent monotherapies fail, a combination therapy may be useful. Drugs may be tapered over 6 weeks to 3 months, gradually. Duration of treatment depends on the type of epilepsy, etiology \& time to seizure control, generally a therapy for a period of $2-5 \mathrm{yrs}$ is considered before withdrawing AEDs.

Ketogenic diet is effective natural treatment for seizures in CP refractory to antiepileptic drugs at nontoxic levels. Low carbohydrates and high fat diet modify the metabolism and increase ketone bodies which reduces the frequency of seizures. This diet is most effective in infants and young children. It is effective for control of myoclonic seizure, infantile spasm, atonic seizure, mixed seizure of Lennox Gastaut syndrome. It is natural treatment for seizure in CP.

Old Antiepileptic Drugs: First antiepileptic in 1857 by Charles Locock with the introduction of potassium bromide as a treatment of epilepsy.In 1912- phenobarbitone \& after 20 years, phenytoin by Merritt\& Putman.

Drugs available are - Valproate, Carbamazepine, Phenytoin, Clonazepam, Diazepam, Lacosamide, Ethosuximide etc.

\section{Mechanism of action of AEDs-}

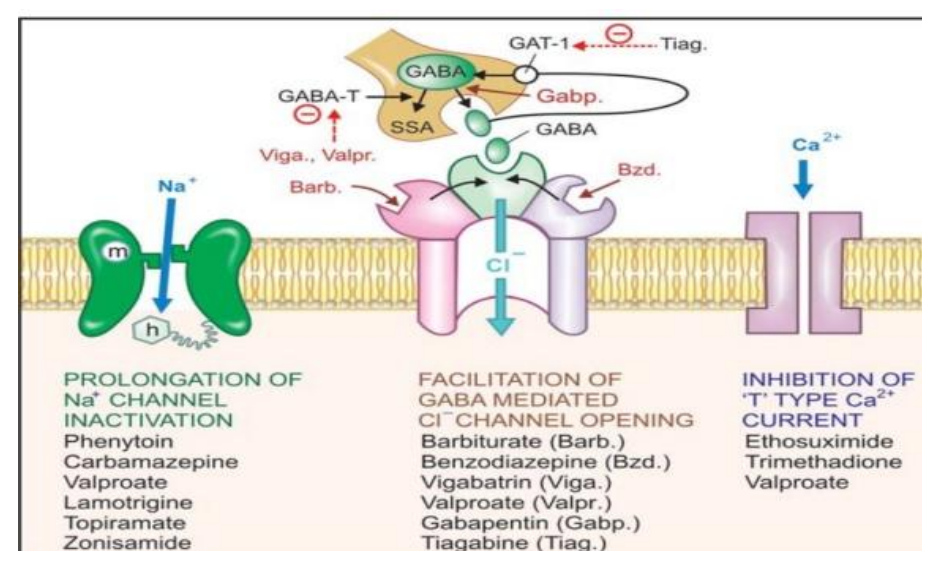

New antiepileptic drugs- Levetracitam, Topiramate, Zonisamide, Rufinamide, Lamotrigine, Felbamate, Stiripentol

Under trial drugs- Eslicarbazepine,Tigabine, Ezogabine, Perampanel, Brivaracetam.

\section{Older versus newer drugs}

$>$ Older drugs: Mechanism of action- Works on $\mathrm{Na}^{2+}$ and GABA Channel.Efficacy similar, Drug interaction- Induce cytochrome P450 (Phenytoin, Phenobarbitone, Carbamazepine) or inhibit it (Valproate).Strongly affects hormone and bone metabolism; Adverse drug reactions- more common; Teratogenecityhigh.

$>$ Newer drugs-Novel mechanism as $\mathrm{K}^{+}$ opener, synaptic vesicle $2 \mathrm{a}$ stimulator, GAT-1 opener, $\mathrm{Ca}^{2+}$ channel inhibitor.Less interactions; Less effect on hormones and bone metabolism;Less adverse drug reactions; less teratogenic.

Levetiracetam- Broad spectrum, useful for most of the refractory seizures.Its safety, lack of drug interactions and neuroprotective effect makes it an excellent first line of choice for most seizures of CP. Initial dose is $20 \mathrm{mg} / \mathrm{kg}$ iv. Maintenance dose is $10 \mathrm{mg} / \mathrm{kg}$ bid or tds.Side effect- cranky, adding small doses of pyridoxine is effective $(50 \mathrm{mg})$.

Topiramate- Used for seizure in>3yrs but recent recommendation approved its use in neonates also because it is neuroprotective like levetriacetam. Dose is $1-2 \mathrm{mg} / \mathrm{kg} / \mathrm{day}$; can be increased up to $15 \mathrm{mg} / \mathrm{kg} /$ day. Only oral formulation is available. It is excellent AED for obese children, who are prone to develop obesity with other drugs because it causes weight loss.Advise to take plenty of water to avoid renal stone formation.

Felbamate - Wide spectrum, used for refractory partial \& generalized seizures. Rapidly absorbed after oral intake. Initial dose- $15 \mathrm{mg} / \mathrm{kg} /$ day TDS. Avoid night time dose- causes insomnia. Increase weekly doses of $15 \mathrm{mg} / \mathrm{kg}$ as needed to a total dose of $45 \mathrm{mg} / \mathrm{kg} /$ day. Side effects- fetal liver damage and most commonly aplastic anaemia. 
Lamotrigine - Used in children >2yrs of age. Spectrum of activity is similar to valproate. Useful in absence, atonic, juvenile myoclonic epilepsy (JME), Lennox Gestaut, partial \& GTCS. Dose if monotherapy- $0.3 \mathrm{mg} / \mathrm{kg} /$ day.If use with valproate- dose is $0.15 \mathrm{mg} / \mathrm{kg} /$ day.As enzyme inducer- $0.6 \mathrm{mg} / \mathrm{kg} /$ day. Maximum dose- $5-7$ $\mathrm{mg} / \mathrm{kg} /$ day in monotherapy.With valproate- 1-3 $\mathrm{mg} / \mathrm{kg} /$ day, With phenobarbitone- $5-15 \mathrm{mg} / \mathrm{kg} /$ day. Side effect- rash. It has beneficial effect on cognition.

Zonisamide- It also has broad spectrum activity. Effective for primary generalized and partial onset seizure, myoclonic seizure. Dose- $2 \mathrm{mg} / \mathrm{kg} / \mathrm{day}$. Maximum dose is around $15 \mathrm{mg} / \mathrm{kg} / \mathrm{day}$. Side effects- Drowsiness, anorexia, oligohidrosis etc.

Rufinamide- Used for patients who have Lennox Gastaut syndrome and seizure for >4yrs. Adjunctive treatment of childhood onset epileptic encephalopathies. Dose- $5-10 \mathrm{mg} / \mathrm{kg} / \mathrm{day}$ with meals. Maximum dose- $45-50 \mathrm{mg} / \mathrm{kg} /$ day.

Stiripentol- Used for severe myoclonic epilepsy of infancy. Efficacy- concomitant juices, caffiene containing drinks \& milk products must be avoided. Dose- $50 \mathrm{mg} / \mathrm{kg}$ in 2-3 divided doses.

Ezogabine- $\mathrm{K}^{+}$channel opener- inhibit smooth muscle contractility; raised concern about its effect on bladder contractility.

Eslicarbamazepine- Greater affinity for inactive state of $\mathrm{Na}^{+}$channels; so, could be selective for rapidly firing neurons.

Perampanel-Used in children $>12$ yrsof age partial onset epilepsy

Brivaracetam- 13 times higher affinity for synaptic vesicle protein $2 \mathrm{~A}$; also inhibit sodium channels.

Tigabine- Effective against partial seizures.Dose$4 \mathrm{mg} /$ day; increase weekly. Side effects- hepatic failure.

\section{Conclusion}

The newer anti-epileptic drugs are proving to have less interactions, less effect on various metabolisms and less adverse effects. So, these should be preferred in the treatment of patients for seizures in cerebral palsy.

\section{References}

1. Nelson Textbook of Pediatrics $21^{\text {st }}$ edition.

2. Fenichel's Clinical Pediatric Neurology.

3. OP Ghai Essential Pediatrics $9^{\text {th }}$ edition.

4. Piyush Gupta PG Textbook of Pediatrics.

5. IAP Textbook of Pediatrics $6^{\text {th }}$ edition. 